\title{
Adult life after surviving lymphoma in childhood
}

\author{
Nicolas X. von der Weid
}

Received: 3 July 2007 / Accepted: 4 December 2007 /Published online: 15 January 2008

(C) Springer-Verlag 2007

\begin{abstract}
Introduction Almost all pediatric lymphomas are malignant, high-grade tumors. The combined incidence of Hodgkin's disease (HD) and non-Hodgkin lymphoma (NHL) reaches 10 to 12 new cases a year per million children under the age of 16 years, representing about $10 \%$ of all pediatric cancers. HD makes up to $40 \%$ and NHL $60 \%$ of pediatric lymphomas. During the last 20 years, cure rates raised dramatically so that currently over $90 \%$ of children and adolescents with HD and about $80 \%$ of those with NHL can be cured. As cure can be achieved in a large majority of patients, long-term effects and quality of life of the survivors are nowadays the principal challenges to pediatric oncologists.

Discussion Like survivors from acute lymphoblastic leukemia, young adults cured from NHL may present with neurocognitive deficits, especially if treated at a young age and with cranial irradiation. Intrathecal or high-dose intravenous chemotherapy with methotrexate may induce the same problems, although in a lesser extent and severity. Large enough prospective cohort studies like the CCSS in the USA were able to show an increased risk of second malignant neoplasms, especially brain tumors in patients formerly treated with cranial irradiation. Reduced fertility can follow exposure to cyclophosphamide, especially in the
\end{abstract}

Presented at This paper has been presented as invited lecture at the MASCC/ISOO 20th Anniversary International Symposium Supportive Care in Cancer in St-Gallen, June 29, 2007.

N. X. von der Weid $(\bowtie)$

Department of Pediatrics, Pediatric Hematology-Oncology Unit, University Hospital,

1011 Lausanne-CHUV,

Lausanne, Switzerland

e-mail: Nicolas.von-der-Weid@chuv.ch male. Cardiac function must be serially evaluated over the long to very long-term because of potential cardiomyopathy after high anthracycline doses and/or mediastinal irradiation.

Survivors from HD are at high risk of late complications. Radiation therapy to the neck and mediastinum (mantle field) induces a $50 \%$ risk of developing hypothyroidism and a $20 \%$ risk of developing thyroid nodules at 20 years. The risk of thyroid cancer is 18 times higher the expected rate for the general population. Secondary aggressive breast cancer shows a cumulative risk of $30 \%$ at 30 years after radiotherapy. Other structures affected by mediastinal irradiation are the heart (pericardial, myocardial and endocardial structures), the great arteries (fibrosis, stenosis, aneurysms) and the central portion of the lungs (diffusion troubles, restrictive pneumopathy). Cardiac toxicity can be enhanced by the concomitant therapy with adriamycin and lung toxicity by bleomycin. Radiotherapy to the paraaortic and iliacal lymph nodes can affect gonadal function both in males and females; concomitant chemotherapy with alkylating agents like cyclophosphamide and especially procarbazine have a synergistic action and can lead to premature menopause as well as infertility.

Although the vast majority of survivors from pediatric lymphomas fare well, a minority present with extreme symptoms of depression and psychosomatic distress; female sex, low socio-economic status and treatment with intensive chemotherapy are important risk factors for a poor psychosocial outcome.

Conclusion It is therefore crucial, but not always easy, to inform patients and families about potential late effects and organize follow-up after the pediatric age. A well functioning network of pediatric oncologists, GP's, adult oncologists and other specialists of adult medicine must be developed in order to prevent, early detect and treat expected long-term toxicities. 
Keywords Lymphoma $\cdot$ Children · Pediatric · Adult life . Late effects

\section{Introduction}

During the last 40 years, dramatic improvements have been achieved in the treatment of pediatric lymphomas. In Hodgkin's disease, over $90 \%$ of patients can be cured; in non-Hodgkin's lymphoma (NHL) about $80 \%$. With improved survival, concerns and issues related to longterm toxicities and quality of life of the survivors become a crucial point of interest.

In this paper, we will review selected late effects, focusing on those with the major impact on late mortality or morbidity and on health-related quality of life. These include second malignancies, cardiotoxicity, endocrine and neuropsychological deficits.

Two main challenges arise when studying late complications of childhood cancer. The first is the fact that treatments continuously evolve over time and the second is the occurrence of very late complications of treatments applied three or more decades ago. As treatment- and patient-related factors impact the risk of late adverse outcomes, it is essential to clearly delineate those survivors at high risk of specific complications for the rational design of the medical follow-up and the implementation of preventive and interventional measures.

\section{Second malignancies}

Survivors of pediatric and adolescent Hodgkin's disease clearly represent a subgroup of patients at high- to very high risk of secondary malignancies. This is particularly true for those children treated many decades ago with predominantly radiation-based therapies: they show an approximately tenfold increased risk of developing a second cancer [25]. MOPP or COPP (mechlorethamine, cyclophosphamide, vincristine, procarbazine, prednisone) based regimens significantly increase the risk for secondary leukemias [38, 15]. Classically, these alkylating-agentsrelated leukemias arise early ( 2 to 10 years, mean 7 years) after Hodgkin's treatment, show typical cytogenetical abnormalities (e.g. monosomy 5 or 7) and often develop as acute myeloid leukemia (AML) on the background of a myelodysplastic syndrome [9]. Interestingly, patient-related factors identified as polymorphisms in specific drugmetabolizing enzymes modulate the risk of developing secondary leukemias. Patients with the NQO1 (NAD(P)H: quinine oxydoreductase) polymorphism are statistically at higher risk of developing therapy-related AML and myelodysplasia $[2,24]$. Individuals with the CYP3A4-W genotype accumulate intermediate reactive metabolites that may damage DNA [10].

Breast cancer is the most frequent secondary solid tumor reported in Hodgkin's disease female survivors treated with mantle field radiation but has also been described in males. In contrast to secondary leukemias, the incidence of solid tumors doesn't plateau after 10 years but shows a continuous increase over time $[22,25]$. In a recent paper from the Childhood Cancer Survivors Study (CCSS, the world's largest cohort of pediatric cancer survivors with currently more than 25,000 people in follow-up), Bathia et al. [1] reported on a cumulative incidence of developing a secondary breast carcinoma approaching $20 \%$ at 45 years of age. Typically, these cancers are located in the internal quadrants of the breast, frequently (in about $40 \%$ of cases) bilateral and biologically more aggressive than primary breast cancer. The second most frequent radiation-induced cancer is thyroid carcinoma, which again occurs more frequently in women and at about a 36-fold increased rate compared to the general population. Iterative screening by cervical ultrasound is important in order to detect tumors at an early stage and be curative with surgery only.

With the growing and ageing population of survivors, excess risks for other solid tumors like lung, gastrointestinal carcinomas but also bone and brain tumors have already been disclosed in the early cohorts [20].

Second malignancies are significantly more uncommon in survivors from NHL (Table 1). Like in acute lymphoblastic leukemia (ALL), most of them are brain tumors and thyroid carcinomas in patients formerly treated with CNS radiation. Here again, besides these treatment-related factors, patient-related ones could be highlighted. An earlier age at diagnosis and specific genetic polymorphisms, like thiopurine $S$-methyltransferase (TPMT), were predictive of the risk of secondary CNS tumors in ALL survivors [30]. Secondary AML has been described in patients with ALL and NHL formerly treated with epipodophyllotoxins (topoisomerase-II inhibitors). This kind of secondary AML is characterized by an earlier onset ( 3 to 5 years from NHL therapy) as alkylating-agents-associated AML, by the presence of 11q23 rearrangements (mutations in the MLL gene) and is more dependent on the administration's schedule than on the cumulative dose [29, 37] (Tables 2 and 3).

\section{Cardiotoxicity}

Survivors from pediatric Hodgkin's disease, especially those treated in early eras, are at increased risk for late cardiac complications and even cardiac death. Mantle field irradiation at doses around or above 40 Gy can induce damages to the three main cardiac components: pericardium with chronic constrictive pericarditis as a late consequence; 
Table 1 Occurrence of second malignancies among 5-year survivors of childhood leukemia and lymphoma (adapted from Neglia et al. [25])

\begin{tabular}{llll}
\hline Diagnosis & $\begin{array}{l}\text { Observed/expected ratio } \\
(95 \% \text { confidence interval })\end{array}$ & $\begin{array}{l}\text { Cumulative } \\
\text { incidence at } \\
\text { 20 years }\end{array}$ & $\begin{array}{l}\text { Absolute } \\
\text { excess of } \\
\text { risk }^{\mathrm{a}}\end{array}$ \\
\hline Leukemia & $5.66(4.37-7.22)$ & $2.1 \%$ & 1.2 \\
Hodgkin's & $9.70(8.05-11.59)$ & $7.6 \%$ & 5.13 \\
NHL & $3.21(1.76-5.39)$ & $1.9 \%$ & 0.89 \\
\hline
\end{tabular}

${ }^{a}$ Risk is expressed at number of malignancies per 1,000 person-years of follow-up

myocardial fibrosis and endocardial thickening and valvular stenoses or insufficiencies. In a small unpublished series of 76 Swiss Hodgkin's survivors treated between 1970 and 1985 and evaluated in the year 2000, we found an $18 \%$ prevalence of late, asymptomatic cardiac injuries; endocardial and valvular damage represented one half of this burden, myocardial disease (dilated cardiomyopathy) one third and pericardial damage the rest.

Furthermore, post-actinic changes affecting the great vessels as well as the coronary arteries have been described in survivors from early cohorts having received high doses of mantle field radiation without optimal cardiac shielding [7]. Premature atherosclerosis and acute myocardial infarction are relevant complications of mediastinal irradiation. In the Stanford series [12], there is a 45 -fold excess mortality risk from acute myocardial infarction in patients treated with more than 30 Gy of mediastinal irradiation before the age of 20 years. With lower volumes and doses of radiation combined with optimal cardiac shielding, the risk of radiation-induced cardiac injury can be dramatically reduced. In a very recent study from Toronto [5] reporting on children and adolescents treated in the 90s with MOPP/ABV and low-dose (15 Gy) radiation, late cardiac complications were found in only one $(2.5 \%)$ of 43 survivors assessed with echocardiography 5 years after therapy.

Anthracycline-induced cardiomyopathy is a well documented late to very late effect in adult survivors from both pediatric Hodgkin's and non-Hodgkin's lymphomas. In Hodgkin's disease, drug-induced toxicity often adds to the radiation-induced toxicity discussed above; in NHL patients, daunorubicin or doxorubicin alone can induce myocardial damage in a dose-dependent way. A cumulative anthracycline dose greater than $300 \mathrm{mg} / \mathrm{m}^{2}$ is associated with an 11-fold increased risk of clinically relevant heart failure, the risk increasing with the length of follow-up and approaching 5\% at 15 years after exposure [17]. When looking at subclinical myocardial damage, studying left ventricular morphology and function, numbers vary considerably from one to the other study (from 0 to $57 \%$ ) mainly because of methodological differences: definition of outcomes, heterogeneity of the patient populations studied, etc. [18]. This makes an accurate evaluation of the potential long-term cardiac outcomes in anthracycline-exposed patients very difficult, especially if considering also subclinical findings; it is probably correct to state that there may be no safe anthracycline dose to completely avoid late cardiotoxicity.
Table 2 Common late effects after treatment for Hodgkin's disease in childhood (adapted from Robison and Bathia [32])

AML Acute myeloid leukemia, CHF congestive heart failure, CNS central nervous system, $P T S D$ post-traumatic stress disorder, $T x$ therapy, XRT radiation therapy

\begin{tabular}{|c|c|c|}
\hline Adverse outcome & $\begin{array}{l}\text { Treatment associated } \\
\text { with an increased risk }\end{array}$ & Factors associates with highest risk \\
\hline Hypothyroidism & XRT to the thyroid & Increasing dose, females \\
\hline Hypogonadism & $\begin{array}{l}\text { Alkylating agents, } \\
\text { pelvic XRT }\end{array}$ & $\begin{array}{l}\text { Males, pubertal age at Tx in girls, higher } \\
\text { dose of alkylators }\end{array}$ \\
\hline Breast cancer & XRT to the chest & Increasing dose, females \\
\hline $\begin{array}{l}\text { Myelodysplastic } \\
\text { syndrome/AML }\end{array}$ & $\begin{array}{l}\text { Alkylating agents, } \\
\text { topoisomerase-II } \\
\text { inhibitors }\end{array}$ & $\begin{array}{l}\text { Increasing dose of alkylators, older } \\
\text { age at } \mathrm{Tx}\end{array}$ \\
\hline Thyroid cancer & XRT to the thyroid & $\begin{array}{l}\text { Increasing dose, females, younger age } \\
\text { at XRT }\end{array}$ \\
\hline Skin cancer & XRT & $\begin{array}{l}\text { Orthovoltage XRT; higher dose to the skin, } \\
\text { additional excessive exposure to sun, } \\
\text { tanning baths }\end{array}$ \\
\hline Cardiomyopathy/CHF & Anthracyclines & $\begin{array}{l}\text { High cumulative dose, females younger } \\
\text { than } 5 \text { years at } \mathrm{Tx}\end{array}$ \\
\hline Pulmonary fibrosis & $\begin{array}{l}\text { Bleomycin, XRT to the } \\
\text { chest, carmustine }\end{array}$ & $\begin{array}{l}\text { Younger age at Tx, bleomycin } \\
\text { dose }>400 \mathrm{U} / \mathrm{m}^{2}\end{array}$ \\
\hline Myocardial infarction & XRT to the chest & $\begin{array}{l}\text { Underlying risk factors (smoking, } \\
\text { hypertension, hyperlipidemia, obesity, etc.) }\end{array}$ \\
\hline $\begin{array}{l}\text { Psychosocial outcomes } \\
\text { (depression, anxiety, PTSD) }\end{array}$ & & Females \\
\hline
\end{tabular}


Table 3 Common late effects after treatment for NHL in childhood (adapted from Robison and Bathia [32])
$A M L$ Acute myeloid leukemia, $C H F$ congestive heart failure, CNS central nervous system, $P T S D$ post-traumatic stress disorder, $T x$ therapy, XRT radiation therapy

\begin{tabular}{|c|c|c|}
\hline Adverse outcome & $\begin{array}{l}\text { Treatment associated with an } \\
\text { increased risk }\end{array}$ & Factors associates with highest risk \\
\hline Neurocognitive deficits & Cranial XRT & $\begin{array}{l}\text { Females, younger age at Tx, increasing } \\
\text { XRT dose }\end{array}$ \\
\hline Hypothyroidism & XRT to the thyroid & Increasing dose, females \\
\hline Hypogonadism & $\begin{array}{l}\text { Alkylating agents; } \\
\text { craniospinal, pelvic or } \\
\text { gonadal XRT }\end{array}$ & $\begin{array}{l}\text { Males, pubertal age at Tx in girls, higher } \\
\text { dose of alkylators }\end{array}$ \\
\hline Osteopenia, osteoporosis & $\begin{array}{l}\text { Steroids, Methotrexate; cranial, } \\
\text { pelvic or gonadal XRT, }\end{array}$ & $\begin{array}{l}\text { Associated hypothyroidism, hypogonadism } \\
\text { or GH-deficiency }\end{array}$ \\
\hline $\begin{array}{l}\text { Avascular necrosis } \\
\text { of bone }\end{array}$ & $\begin{array}{l}\text { Steroids, high-dose XRT } \\
\text { on bone }\end{array}$ & Dexamethasone, adolescents, males \\
\hline Secondary CNS tumor & Cranial XRT & Increasing XRT dose, younger age at Tx. \\
\hline $\begin{array}{l}\text { Myelodysplastic } \\
\text { syndrome, Secondary } \\
\text { AML }\end{array}$ & $\begin{array}{l}\text { Alkylating agents, } \\
\text { topoisomerase-II inhibitors }\end{array}$ & $\begin{array}{l}\text { Increasing dose of alkylators, older age } \\
\text { at } \mathrm{Tx}\end{array}$ \\
\hline Skin cancer & XRT & $\begin{array}{l}\text { Orthovoltage XRT; higher dose to the skin, } \\
\text { additional excessive exposure to sun, } \\
\text { tanning baths }\end{array}$ \\
\hline Cardiomyopathy/CHF & Anthracyclines & $\begin{array}{l}\text { High cumulative dose, females younger } \\
\text { than } 5 \text { years at } T x\end{array}$ \\
\hline Dental abnormalities & Cranial XRT & Younger age at $\mathrm{Tx}$ \\
\hline
\end{tabular}

\section{Endocrine sequelae}

Radiation therapy to the neck (upper part of the mantle field) is a well known risk factor for subsequent thyroid disease. In survivors from Hodgkin's disease and in a markedly lesser extent from NHL, hypothyroidism, hyperthyroidism and benignant or malignant thyroid nodules have been described. In a recent study from the CCSS [36], about $34 \%$ of 1,791 5-year Hodgkin's survivors had at least one thyroid abnormality, hypothyroidism clearly being the most frequent. In our own unpublished series (see above), we found an overall prevalence of hypothyroidism reaching $43 \%$, with a clear-cut dose-effect relationship: the prevalence was $51 \%$ in patients treated with $35-45$ Gy compared to $27 \%$ in patients treated with $15-25$ Gy $(p<0.05$ in the $\mathrm{Chi}^{2}$ test).

Growth hormone deficiency with poor linear growth and reduced final height is a common complication of CNS irradiation at doses above 15 to $18 \mathrm{~Gy}$, typically in the dose range used for prophylactic CNS treatment in acute lymphoblastic leukemia and some, especially T-cell, NHL's. In chemotherapy-only treated patients with ALL or NHL, the prevalence of short stature is very low, although there are some conflicting results in the literature regarding the impact of chemotherapy on final height $[16,35]$.

Cranial irradiation has also been recently related to an increased prevalence of adult overweight (BMI 25-30) and obesity (BMI >30), especially in female long-term survivors of ALL followed in the CCSS [27]. Besides gender, age at diagnosis of ALL was significantly correlated to the risk of overweight/obesity, girls diagnosed under the age of 4 years and treated with $>20$ Gy of cranial irradiation showing an almost fourfold increase risk of obesity compared to adult siblings of cancer survivors.

Both pelvic irradiation (infra-diaphragmatic inverted-Y field) and alkylating agents like mechlorethamine, cyclophosphamide and procarbazine (in MOPP and COPP regimens) are highly gonadotoxic and primary gonadal failure has been described both in male and female survivors from Hodgkin's disease [8]. Pelvic radiation is extremely deleterious to the germinal epithelium of the testes and ovaries, leading to impaired fertility or sterility, even after very low exposures (4 to 6 Gy) [34]. In males, Leydig cell function is rarely affected with usually normal pubertal development, testicular volume and sexual function. On the other hand, sterility is a big issue in male survivors. Oligospermia may already exist at the time of diagnosis in 30 to $40 \%$ of patients [4] but, despite of this, sperm cryopreservation should always be considered before initiating therapy in pubertal boys. Six to eight MOPP or COPP cycles will lead to azoospermia in 80 to $90 \%$ of survivors [21]. However, late (10 to 15 years later) recovery of fertility has also been reported $[6,28]$, so that caution is always required when discussing this prognosis with the patients. Anthracycline (ABVD) or epipodophyllotoxinbased (OEPA) regimens are distinctly less gonadotoxic but also possibly less effective. In women, the deleterious effects of pelvic irradiation can be prevented by the surgical transfer of the ovaries to the midline (oophoropexy) [19]. Effects on the ovaries are very dependent on the age of the 
woman at the time of therapy, with younger girls having the higher probability of maintaining regular menses after treatment [28]. Normal pregnancies can occur after oophoropexy and pelvic irradiation without increased risk of fetal wastage or spontaneous abortion [14]. No increase in birth defects could be observed in offspring of survivors when compared with those of sibling controls. Treatment for girls and teens with Hodgkin's disease may carry a considerable risk of endocrine ovarian failure, i.e. premature menopause. As expected, females treated with alkylating agents and inverted-Y irradiation have a 27 -fold increased probability of premature menopause: $42 \%$ of these women had reached menopause at the age of 31 years compared to $5 \%$ in the controls [3].

NHL survivors, like their ALL counterparts, are at lowrisk of infertility and delayed or impaired puberty, especially if treated with modern conventional therapy. The figure is clearly different in the subgroup of children having needed an allogeneic bone marrow transplant, where alkylating-based conditioning regimens and/or total body irradiation show the same deleterious effects as in Hodgkin's disease [33].

\section{Neuropsychological effects}

Because of the lack of CNS damaging agents (neither in the radiation nor in the chemotherapy) in the treatment of Hodgkin's disease, survivors don't present with relevant neurocognitive deficits when compared to normal sibling controls. However, a recent analysis from the CCSS [41], noted that NHL but also Hodgkin's survivors were significantly more likely to report depression or somatic distress than sibling controls. Furthermore, there is a recently growing interest in the prevalence of sleep disturbances and chronic fatigue syndrome in Hodgkin's survivors [11] which might contribute to depression in those patients.

Neuropsychological or neurocognitive sequelae are among the most intensively studied topics in long-term survivors of childhood ALL. Because of the mentioned biological and therapeutical similarities between ALL and NHL, most authors analyze these patients as a single group. Main risk factors described in earlier studies were cranial irradiation, young age at treatment and, although somewhat more controversial, female sex [26, 13]. These outcome studies have been directly responsible for the dramatic reduction or even discarding of cranial irradiation for most of these patients, especially those from the youngest age groups. Unfortunately, late cognitive deficits, mainly attention/concentration troubles, impaired auditive and visual short-term memory and reduced speed of processing leading to poor academic achievement have also been observed after chemotherapy-only regimens in ALL and NHL [23]. In the
Swiss Late Effects Study [39], neuropsychological outcomes of 35 CNS-irradiated and 106 non-irradiated (chemotherapyonly) patients were compared using the full version of the WISC-R ${ }^{\circledR}$ or WAIS-R ${ }^{\circledR}$ test. Statistically significant lower scores in global and verbal IQ's were found in formerly irradiated children. Looking at the single items of the Wechsler test, significantly lower scores were also found in arithmetics, short-term verbal memory, speed of processing and visuo-motor coordination, always in the group of irradiated children. Globally, only $18 \%$ of the 141 survivors presented with learning disabilities and $94 \%$ followed a normal schooling. Looking at the chemotherapy-only subgroup in more details and comparing it with survivors from pediatric non-CNS solid tumors, we found that the global intellectual performance as well as the proportion of patients with learning disabilities (gIQ between 70 and 85) was the same in both groups. Children younger than 6 years at diagnosis and girls had significantly lower IQ scores than older children and boys respectively [40]. Summarizing the findings from both our studies and others, it can be said that skipping cranial radiotherapy and replacing it with more intensive systemic and intrathecal chemotherapy is feasible in most ALL/NHL patients, oncologically as efficient as prophylactic cranial irradiation and leads to a significant reduction of the burden of late neuropsychological deficits.

\section{Outlook}

It is crucial to keep in mind that the late effects we observe today are the consequence of Hodgkin's and non-Hodgkin's lymphoma treatment strategies applied 20 to 30 years ago. Knowledge gained on the prevalence of late to very late toxicities led to the design of newer treatment strategies, able to maintain excellent survival while reducing longterm mortality and morbidity. An example of such an improvement can be found in the aforementioned publication from the Toronto group in Hodgkin's disease [5]: in spite of an impressive reduction in chemo- and radiotherapy intensity, no negative impact was found on 10-year EFS or OS (88 vs 94\%) and only four (3.5\%) out of 116 survivors developed a second malignant neoplasm after a median follow-up of 8.5 years. Prevalences of thyroid damage, cardiac and pulmonary late effects were also dramatically lower than in older cohorts, reaching only $14.5 \%, 2.5 \%$ and $8 \%$ respectively. Basing on the excellent results of the German (GPOH) study, a newer protocol for Hodgkin's lymphoma has just been released at the European level (EuroNet-PHL-C1): basing on the results of the Positron Emission Tomography-Computed Tomography (PET-CT) scan after the first two OEPA courses, all patients with a negative PET will avoid exposure to radiotherapy. Post- 
induction chemotherapy will be randomized between the standard COPP and a less gonadotoxic COPDAC regimen.

There will be an ongoing need to systematically follow these adolescents and young adults cured with these new therapies. In order to get sufficient power, late-effects studies will require to be done in the context of large, multi-institutional and international initiatives. American and European collaborative groups designing clinical trials should be the leaders in establishing these long-term cohorts, as done with the Childhood Cancer Survivor Study [31]. With such an interdisciplinary approach, the goal of cure while minimizing late effects is clearly achievable.

\section{References}

1. Bhatia S, Robison LL, Meadows AT, LESG Investigators (2001) High risk of second malignant neoplasms (SMN) continues with extended follow-up of childhood Hodgkin's disease (HD) cohort: report from the Late Effects Study Group. Blood 98:768a

2. Blanco JG, Edick MJ, Hancock ML, Winick NJ, Dervieux T, Amylon MD, Bash RO, Behm FG, Camitta BM, Pui CH, Raimondi SC, Relling MV (2002) Genetic polymorphisms in CYP3A5, CYP3A4 and NQO1 in children who developed therapy-related myeloid malignancies. Pharmacogenetics 12:605-611

3. Byrne J, Fears TR, Gail MH (1992) Early menopause in long-term survivors of cancer during adolescence. Am J Obstetr Gynecol 166:788-793

4. Chapman RM, Sutcliffe SB, Malpas JS (1979) Cytotoxic-induced ovarian failure in women with Hodgkin's disease. I. Hormone function.. J Am Med Assoc 242:1877-1881

5. Chow LML, Nathan PC, Hodgson DC, Jenkin D, Weitzman S, Grant RM, Manson D, Bross A, Doyle JJ, Danjoux C, Greenberg ML (2006) Survival and late effects in children with Hodgkin's lymphoma treated with MOP/ABV and low-dose, extended-field irradiation. J Clin Oncol 24:5735-5741

6. de Cunha MF, Meistrich ML, Fuller LM (1984) Recovery of spermatogenesis after treatment for Hodgkin's disease: limiting dose of MOPP chemotherapy. J Clin Oncol 2:571-578

7. Donaldson SS, Kaplan HS (1982) Complications of treatment of Hodgkin's disease in children. Cancer Treat Rep 66:977-983

8. Dreyer ZE, Blatt J, Bleyer A (2002) Late effects of childhood cancer and its treatment. In: Pizzo PA, Poplack DG (eds) Principles and Practice of Pediatric Oncology. vol. 4. Lippincott and Wilkins, Philadelphia, pp 1431-1461

9. Felix CA (1998) Secondary leukemias induced by topoisomerasetargeted drugs. Biochim Biophys Acta 1400:233-255

10. Felix CA, Walker AH, Lange BJ, Williams TM, Winick NJ, Cheung NK, Lovett BD, Nowell PC, Blair LA, Rebbeck TR (1998) Association of CYP3A4 genotype with treatment-related leukemia. Proc Natl Acad Sci USA 95:13176-13181

11. Green DM, Zevon MA, Rock KM, Chavez F (2002) Fatigue after treatment for Hodgkin's disease during childhood or adolescence. Proc Am Soc Clin Oncol 21:396a

12. Hancock SL, Donaldson SS, Hoppe RT (1993) Cardiac disease following treatment of Hodgkin's disease in children and adolescents. J Clin Oncol 11:1199-1203

13. Hertzberg H, Huk WJ, Ueberall MA, Langer T, Meier W, Dopfer R, Skalej M, Lackner H, Bode U, Janssen G Zintl F, Beck JD (1997) CNS late effects after ALL therapy in childhood. Part I: neuroradiological findings in long-term survivors of childhood
ALL. An evaluation of the interferences between morphology and neuropsychological performance. The German Late Effects Working Group. Med Ped Oncol 28:387-400

14. Horning SJ, Hoppe RT, Kaplan HS (1981) Female reproductive potential after treatment for Hodgkin's disease. N Engl J Med 304:1377-1381

15. Kaldor JM, Day NE, Clarke EA, van Leeuwen FE, Henry-Amar M, Fiorentino MV, Bell J, Pedersen D, Band P, Assouline D, Koch M, Choi W, Prior P, Blair V, Langmark F, Pompe Kern V, Neal F, Peters D, Pfeiffer R, Karjalainen S, Cuzick J, Sutcliffe SB, Somers R, Pellac-Cosset B, Papagallo GL, Fraser P, Storm H, Stovall M (1990) Leukemia following Hodgkin's disease. New Engl J Med 322:7-13

16. Katz JA, Pollock BH, Jacaruso D, Morad A (1993) Final attained height in patients successfully treated for childhood acute lymphoblastic leukemia. J Pediatr 123:546-552

17. Kremer LCM, van Dalen EC, Offringa M, Otenkamp J, Voute PA (2001) Anthracycline-induced clinical heart failure in a cohort of 607 children: long-term follow-up study. J Clin Oncol 19:191-196

18. Kremer LCM, van der Pal HJH, Offringa M, van Dalen EC, Voute PA (2002) Frequency and risk factors of subclinical cardiotoxicity after anthracycline therapy in children: a systematic review. Ann Oncol 13:819-829

19. Le Floch O, Donaldson SS, Kaplan HS (1976) Pregnancy following oophoropexy in total node irradiation in women with Hodgkin's disease. Cancer 38:2263-2265

20. Lin HMJ, Teitell MA (2005) Second malignancy after treatment of pediatric Hodgkin's disease. J Pediatr Hematol Oncol 27:28-36

21. Mackie EJ, Radford M, Shalet SM (1996) Gonadal function following chemotherapy for childhood Hodgkin's disease. Med Pediatr Oncol 7:74-78

22. Metayer C, Lynch CF, Clarke EA, Glimelius B, Storm H, Pukkala E, Joensuu T, van Leeuwen FE, van't Veer MB, Curtis RE, Holowaty EJ, Andersson M, Wiklund T, Gospodarowicz M, Travis LB (2000) Second cancers among long-term survivors of Hodgkin's disease diagnosed in childhood and adolescence. J Clin Oncol 18:2435-2443

23. Mulhern RK, Reddick WE, Palmer SL, Glass JO, Elkin TD, Kun LE, Taylor J, Langston J, Gajjar A (1999) Neurocognitive deficits in medulloblastoma survivors and white matter loss. Ann Neurol 46:834-841

24. Naoe T, Takeyama K, Yogozawa T, Kiyoi H, Seto M, Uike N, Ino T, Utsunomiya A, Maruta A, Jin-Nai L, Kamada N, Kubota Y, Nakamura H, Shimazaki C, Horiike S, Kodera Y, Saito H, Ueda R, Wiemels J, Ohno R (2000) Analysis of genetic polymorphism in NQO1, GST-M1, GST-T1 and CYP3A4 in 469 Japanese patients with therapy-related leukemia/myelodysplastic syndrome and de novo acute myeloid leukemia. Clin Cancer Res 6:4091-4095

25. Neglia JP, Friedman DL, Yasui Y, Mertens AC, Hammond S, Stovall M, Donaldson SS, Meadows AT, Robison LL (2001) Second malignant neoplasms in five-year survivors of childhood cancer: Childhood Cancer Survivor Study. J Natl Cancer Inst 93:618-629

26. Ochs J, Mulhern R, Fairclough D, Parvey L, Whitaker J, Ch'ien L, Mauer A, Simone J (1991) Comparison of neuropsychologic functioning and clinical indicators of neurotoxicity in long-term survivors of childhood leukemia given cranial radiation or parenteral methotrexate: a prospective study. J Clin Oncol 9:145-151

27. Oeffinger KC, Mertens AC, Sklar CA, Yasui Y, Fears T, Stovall M, Vik TA, Inskip PD, Robison LL (2003) Obesity in adult survivors of childhood acute lymphoblastic leukemia: a report from the Childhood Cancer Survivor Study. J Clin Oncol 21:1359-1365 
28. Ortin TT, Shostak CA, Donaldson SS (1990) Gonadal status and reproductive function following treatment for Hodgkin's disease in childhood: the Stanford experience. Int J Radiat Oncol Biol Phys 19:873-880

29. Pui $\mathrm{CH}$, Relling MV, Rivera GK, Hancock ML, Raimondi SC, Heslop HE, Santana VM, Ribeiro RC, Sandlung JT, Mahmoud HH, Evans WE, Crist WM, Krance RA (1995) Epipodophyllotoxinrelated acute myeloid leukemia: a study of 35 cases. Leukemia 9:1990-1996

30. Relling MV, Rubnitz JE, Rivera GK, Boyett JM, Hancock ML, Felix CA, Kun LE, Walter AW, Evans WE, Pui CH (1999) High incidence of secondary brain tumors after radiotherapy and antimetabolites. Lancet 354:34-39

31. Robison LL, Mertens AC, Boice JD, Breslow NE, Donaldson SS, Green DM, Li FP, Meadows AT, Mulvihill JJ, Neglia JP, Nesbit ME, Packer RJ, Potter JD, Sklar CA, Smith MA, Stovall M, Strong LC, Yasui Y, Zeltzer LK (2002) Study design and cohort characteristics of the Childhood Cancer Survivor Study: a multiinstitutional collaborative project. Med Pediatr Oncol 38:229-239

32. Robison LL, Bathia S (2003) Late effects among survivors of leukemia and lymphoma during childhood and adolescence. Br J Haematol 122:345-359

33. Sanders JE, Hawley J, Levy W, Gooley T, Buckner CD, Deeg HJ, Doney K, Storb R, Sullivan K, Witherspoon R, Appelbaum FR (1996) Pregnancies following high-dose cyclophosphamide with or without high-dose busulfan or total body irradiation and bone marrow transplantation. Blood 87:3045-3052

34. Shamberger RC, Sherins RJ, Rosenberg SA (1981) The effects of post-operative adjuvant chemotherapy and radiotherapy on testicular function in men undergoing treatment for soft-tissue sarcoma. Cancer 47:2368-2374
35. Sklar C, Mertens A, Walter A, Mitchell D, Nesbit M, O'Leary M, Hutchinson R, Meadows AT, Robison L (1993) Final height after treatment for childhood acute lymphoblastic leukemia: comparison of no cranial irradiation with 1800 and 2400 centigrays of cranial irradiation. J Pediatr 123:59-64

36. Sklar C, Whitton J, Mertens A, Stovall M, Green D, Marina N, Greffe B, Wolden S, Robison L (2000) Abnormalities of the thyroid in survivors of Hodgkin's disease: data from the Childhood Cancer Survivor Study. J Clin Endocrinol Metab 85:3227-3232

37. Smith MA, Rubinstein L, Anderson JR, Arthur D, Catalano PJ, Freidlin B, Heyn R, Khayat A, Krailo M, Land VJ, Miser J, Shuster J, Vena D (1999) Secondary leukemia or myelodysplastic syndrome after treatment with epipodophyllotoxins. J Clin Oncol 17:569-577

38. Tucker MA, Coleman CN, Cox RS, Varghese A, Rosenberg SA (1988) Risk of second cancers after treatment for Hodgkin's disease. N Engl J Med 318:76-81

39. von der Weid NX (2001) Late effects in long-term survivors of ALL in childhood: experiences from the SPOG Late Effects Study. Swiss Med Wkly 131:180-187

40. von der Weid NX, Mosimann I, Hirt A, Wacker P, Nenadov Beck M, Imbach P, Caflisch U, Niggli F, Feldges A, Wagner HP (2003) Intellectual outcome in children and adolescents with acute lymphoblastic leukemia treated with chemotherapy alone: ageand sex-related differences. Eur J Cancer 39:359-365

41. Zebrack BJ, Zeltzer LK, Whitton J, Mertens AC, Odom L, Berkow R, Robison LL (2002) Psychological outcomes in longterm survivors of childhood leukemia, Hodgkin's disease and nonHodgkin's lymphoma: a report from the Childhood Cancer Survivor Study. Pediatrics 110:42-52 